\title{
Cases with Familiar Amyloidneuropathy Starting of the upper Limbs and Having Hepatic Disorder
}

\author{
Katsuhiko Tsukada, Masaru OHhashi*, Takashi Isobe** \\ and Kazuo MASUKO ${ }^{* * *}$
}

\begin{abstract}
Here we are reporting two cases consisting of a male patient and his elder sister from Kagashima in Gifu City and both suffering from polyneuropathy of dissociation type and skin amyloidosis. In the former, the presence of amyloid was demonstrated not only in the skin, but also in the stomach, liver and gums. He was also diagnosed suffering from chronic hepatitis of inactive type. He responded to DMSO and Cepharanthin. In the patients, no urinary Bence Jones protein nor blood M component was detected and the amyloid exhibited resistance to potassium permanganate treatment. The neuropathy of the patients were slightly different from that of the Portuguese type which starts on lower extremities as well as those conventionally have been reported in Japan.
\end{abstract}

Key Words: Amyloid neuropathy, Upper extremities, Chronic hepatitis (Non A, Non B)

Familial polyneuropathy found in Japan is said to be of the Portuguese type (I type) and there are two large focuses of this disease in Arao City, Kumamoto $^{1)}$ and Ogawa Village, Nagano. ${ }^{2)}$ Also found is in only one family living in each of Shimane, Hyogo, Kochi and Ishikawa Prefectures. In this paper, we shall report polyneuropathy in a man aged 46 and his elder sister coming from Gifu City (she is now living in Nagoya City). The male patient is a specific case in which neuropathy started on the upper limbs and exhibits chronic hepatitis (Non A, Non B). He has been visiting our hospital for nearly ten years.

Case 1 T.K. (company employee aged 46, living Kagashima in Gifu City)

Past history: Had an operation for empyema at the age of 16.

Family history: As shown in the (Fig. 1) he has 8 siblings, three of which including the patient have dark pigmentation on backs. Of these three persons, his elder sister M.I. will be referred to later as Case 2.

Present illness: Since early in 1977, he visited a hospital in Gifu and for a while had been diagnosed gout, Guillain-Barre syndrome or hepatitis. In those days, he was suffering from diarrhea and constipation. On May 3, 1977, his right palm and forearm felt heavy on getting up in the morning. Three days later, he had severe pains on right palm and forearm. The next day, he had heavy diarrhea

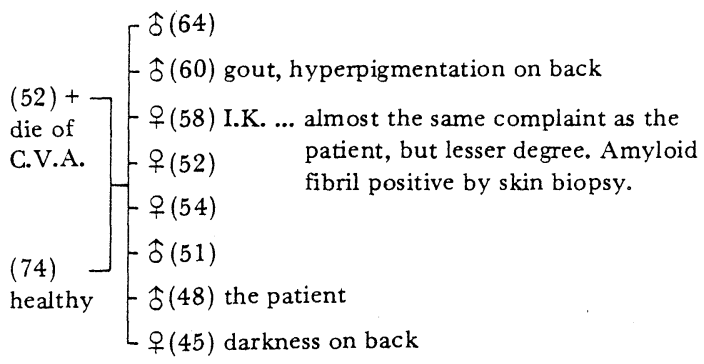

Fig. 1. Pedigree of the patients.

From The First Department of Internal Medicine, Nagoya City University, Nagoya, *Dermatology Department of Nagoya University School of Medicine,

**The Third Division, Department of Medicine, Kobe University School of Medicine, Kobe and

$* * *$ Masuko Hospital and Institute for Medical Research, Nagoya.

Received for publication September 1, 1986.

Reprint request to: Kazuo Masuko, MD, Masuko Hospital and Institute for Medical Research, 35-28, Takehashi-cho, Nakamura-ku, Nagoya 453, Japan. 


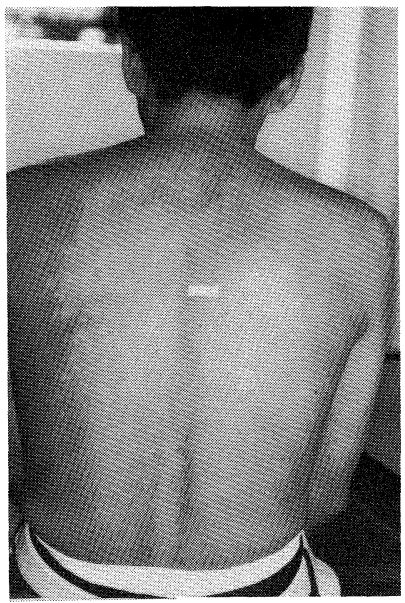

Case 1

Fig. 2. Macular amyloidosis.

with difficulty of delicate hand motions. The pain started from extensor of forearm and then progressed through the right palm toward finger tips. Similar phenomena occurred on the left hand, followed by paraesthesia in the soles of feet.

Physical examination: He first visited our hospital on August 9, 1977. He was a rather short male of a slender figure aged 38 , had the dark colour face with many spots as well as hyperpigmentation with gray speckles scattered over entire body (Fig. 2). Particularly, he revealed a significant degree of gray speckles on his back. Although having no vascular spider over trunk, he showed palm erythema. Beneath the lowest rib palpable was a finger width in length the liver which had a sharp edge without tender. GOT, GPT, total cholesterol and ICG levels were $60 \mathrm{IU}, 109 \mathrm{IU}$, $240 \mathrm{mg} / \mathrm{d} \ell$ and $9.8 \%$ (15 minute value), respectively. The results of the other liver function tests remained within normal ranges. He yielded negative results to HBS antigen and antibody. From the above he was diagnosed chronic hepatitis possibly accompanied by amyloidosis.

Examinations during hospitalization and clinical course: Hospitalized here on Sep. 10, 1980. In the dermatological department, he was diagnosed macular amyloidosis. The skin biopsy indicated deposition of amyloid just below dermis papillae (Figs. 3, 4, 5). Besides, stomach biopsy also performed at this time. The deposition of amyloid fibrils was seen beneath epithelial mucous mem-

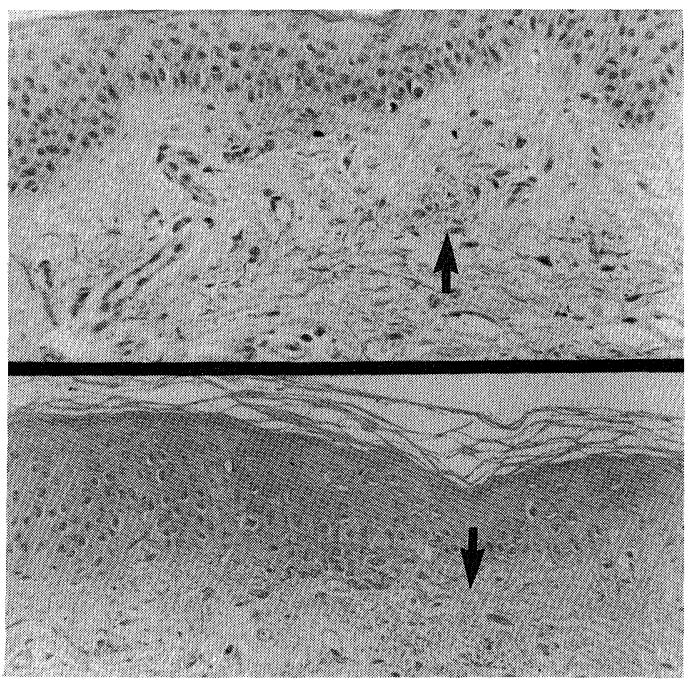

Case 1

Fig. 3. Photomicrograph of skin biopsy stained by alkali-congo red, (upper) arrow shows positive amyloid deposits, (below) pretreated with $\mathrm{KMnO}_{4}$. Notice amyloid deposits made resistance.

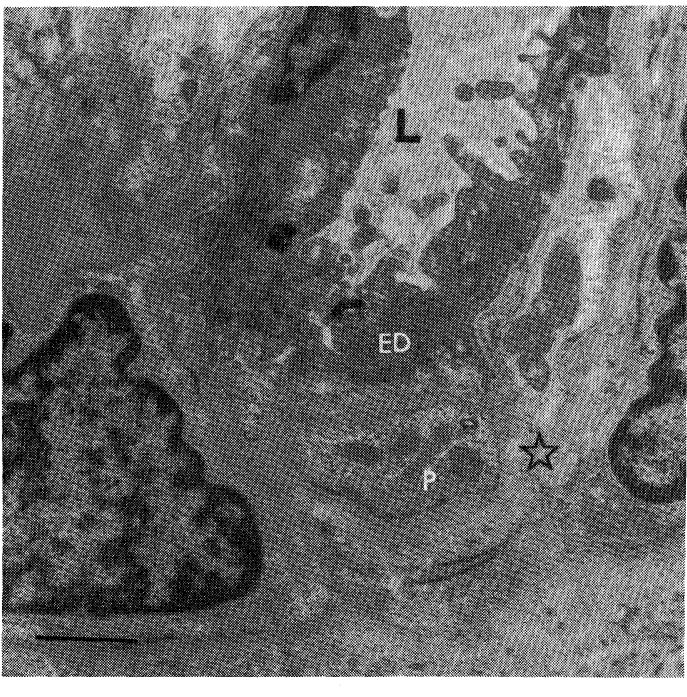

Case 1

Fig. 4. Electron mictoscopic findings of skin L: vascular lumen; ED: endothelial cell; P: pericyte; w: amyloid fibrils. Amyloid fibrils are located around the blood vessel and pericyte.

brane. On Sept. 20, liver biopsy was done under laparoscopy which exhibited non specific hepatitis. The liver biopsy failed to indicate exact hepatitis, but deposition of a small quantity of amyloid was detected on interlobular arterial walls in the 


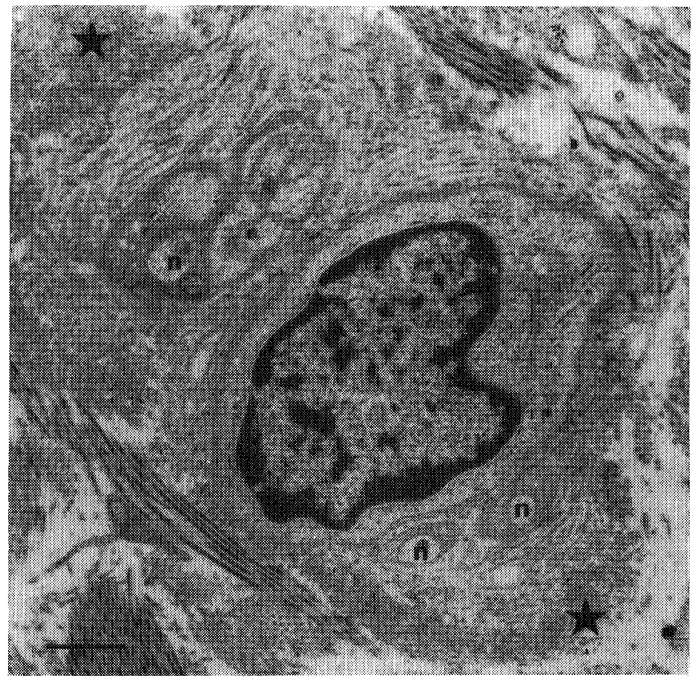

Case 1

Fig. 5. Electron microscopic findings of skin biopsy around neuron. $\mathrm{N}$ : neuron; $\star$ : amyloid filbrils around the neuron are observed.

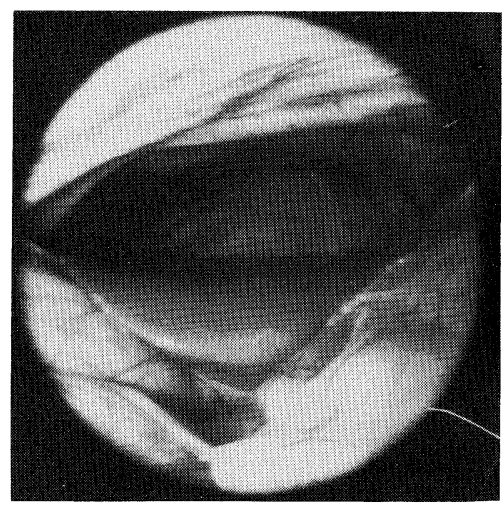

Fig. 6. Peritoneoscopic finding of the liver. Slight uneveness of the surface the edge sharp. It is of pinkish red colour. There is no adhesion nor fibrous deposit.

portal area (Figs. 6, 7). Bone marrow revealed no increase in plasma cells. He complained of numbness on the fifth fingers, flexor of forearms and soles of feet. Itching of skin was alleviated after administration of cepharanthin. ${ }^{3)}$ As to the liver function tests, GOT and GPT levels remained within the ranges of 60-119 IU and 123-122 IU, respectively and slightly high cholesterol levels were recorded. Negative results were found as to urinary protein as well as Bence Jones ${ }^{6)}$ protein (Table 1).

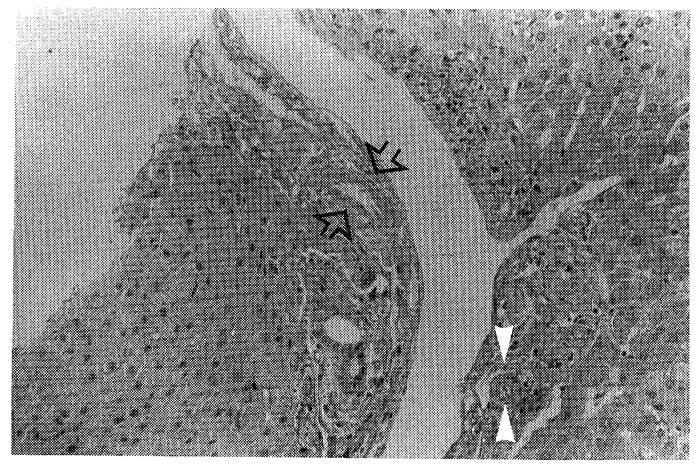

Case 1

Fig. 7. Microscopic findings of liver biopsy specimen. There are amyloid in wall of interlobular arterioles and nearby portal area as well (arrow).

Neurological Examination

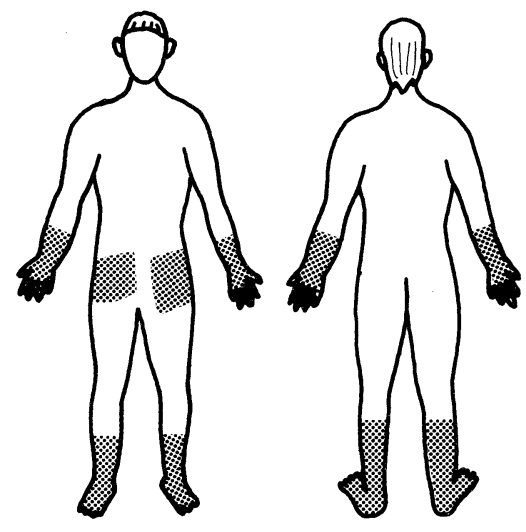

Case 1

Fig. 8. Neurological examination with illustration.

Hypesthesia, hypalgia and vibration disturbance are worse towards periphery. All reflex of extremities lacking, but no pathological ones seen.

He discharged on Nov. 22, 1979.

Clinical course after discharge: After hospitalization, he had such a severe degree of constipation that he had a protruding abdomen on standing. Around June 20, 1980, he complained of complete numbness over the palms and forearms as well as soles of feet and burning sensation in heels, which improved gradually. In Aug. 1980, the severity of numbness in his hands agasin increased following by proceeding from palms to the forearms. In Feb. 1981, he lost feeling more in feet, which was going up to $1 \mathrm{~cm}$ below the knees. As to arms, it proceeded from the fingers up to the 
Table 1. Amyloid deposits on skin, urine excretion of Bence-Jones protein and serum M-P as well as AA.

\begin{tabular}{|c|c|c|c|c|c|c|}
\hline \multirow{2}{*}{ Case } & \multirow{2}{*}{ Age } & \multirow{2}{*}{ Sex } & \multirow{2}{*}{ 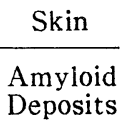 } & \multirow{2}{*}{$\frac{\text { Urine }}{\text { BJP }}$} & \multicolumn{2}{|c|}{ Serum } \\
\hline & & & & & M-P & $\mathrm{AA}$ \\
\hline 1. & 38 & M & + & - & - & - \\
\hline 2. & 48 & $\mathrm{~F}$ & + & - & - & - \\
\hline
\end{tabular}

elbows. The neurological examinations performed at this time were indicative of dissociated anesthesia. $\mathrm{DMSO}^{4)}$ therapy was started on Feb. 24, 1983. The gastrointestinal disorders such as diarrhea and constipation were improved. The neurological disorders observed during this period are as shown in Fig. 8. Having no impotence, he told unusual feeling and pain during ejaculation. As seen from Table 2, the liver function of the patient observed during this period was not different from that observed at the first examination. The conduction rates of peripheral nerves were measured in 1985 . They were markedly decreased on the lower extremities just like disbetic or urenic ones (Fig. 9). Recently he has complained of orthostatic hypotension.

Case 2 M.I. (The elder sister of Case 1)

On Nov. 14, 1979, she visited our hospital for itching of skin. The dermatologist diagnosed lichen and macular amyloidosis (Fig. 10). In May, 1980, she began to complain of paresthesis in the limb

$\begin{array}{lccl}\text { Hand } & \mathrm{R} & \mathrm{L} & \text { Normal range } \\ \text { Median N } & 60.6 & 52.5 & 56.9 \pm 5.8 \mathrm{~m} / \mathrm{sec} \\ \text { ulnar N } & 58.5 & 66.1 & 59.9 \pm 5.7 \mathrm{~m} / \mathrm{sec} \\ \text { Feet } & & & \\ \text { peroneal N } & 48.8 & 45.5 & 52.1 \pm 4.9 \mathrm{~m} / \mathrm{sec} \\ \text { Tibial N } & 42.8 & 38.2 & 49.9 \pm 5.2 \mathrm{~m} / \mathrm{sec} \\ & & \text { Case } 1 & \end{array}$

Fig. 9. Examination of nerve conductive velocity. Notice marked reduction of tibial $\mathrm{N}$.

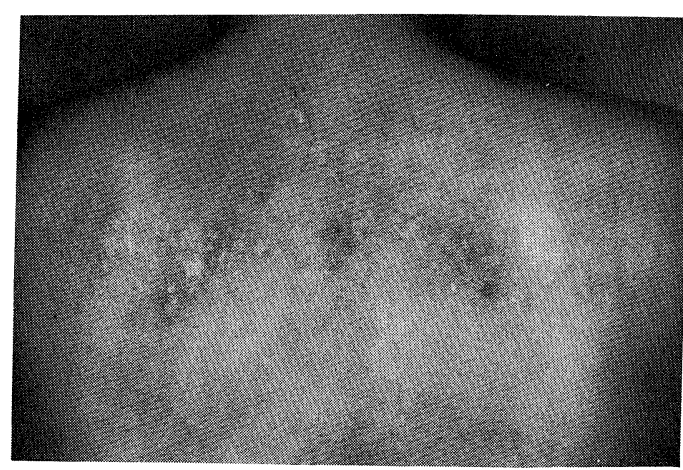

Case 2

Fig. 10. Closer picture of lichen and macular amyloidosis.

\begin{tabular}{|c|c|c|c|c|c|c|c|c|c|c|c|c|}
\hline \multicolumn{2}{|l|}{$23-2$} & \multicolumn{2}{|l|}{ (1979) } & \multicolumn{3}{|c|}{ (1980) } & \multirow{2}{*}{$\begin{array}{c}(1981) \\
2.6\end{array}$} & \multirow{2}{*}{$\begin{array}{c}(1982) \\
2.20\end{array}$} & \multirow{2}{*}{$\begin{array}{c}(1983) \\
12.2\end{array}$} & \multirow{2}{*}{$\begin{array}{l}(1984) \\
10.25\end{array}$} & (1985) & \multirow[b]{2}{*}{10.25} \\
\hline item & normal range & 8.9 & 10.2 & 12.6 & 3. 22 & 8. 29 & & & & & 5.11 & \\
\hline Total Protein & $6.7 \sim 8.3 \mathrm{~g} / \mathrm{dl}$ & 7.2 & 6.6 & 7.3 & 7.1 & 7.1 & 7.5 & 6.9 & 7.4 & 6.6 & 7.0 & 6.6 \\
\hline Total Bilirubin & $0.2 \sim 1.0 \mathrm{mg} / \mathrm{dl}$ & 0.4 & 0.2 & 0.7 & 1.0 & 0.4 & 0.4 & 0.5 & 0.7 & 0.5 & 0.5 & 0.5 \\
\hline Direct bilirubin & $0 \sim 0.4 \mathrm{mg} / \mathrm{dl}$ & 0.1 & 0.1 & 0.2 & 0.2 & 0.1 & 0.2 & 0.2 & 0.2 & 0.3 & 0.2 & 0.3 \\
\hline GOT & $8 \sim 40$ I. U. & 60 & 104 & 91 & 73 & 83 & 60 & 45 & 69 & 67 & 87 & 67 \\
\hline GPT & $5 \sim 35$ I. U. & 109 & 219 & 206 & 173 & 201 & 186 & 61 & 125 & 119 & 147 & 119 \\
\hline LDH & $50 \sim 200$ I. U. & 182 & 199 & 194 & 174 & 183 & 180 & 217 & 214 & 170 & 198 & 170 \\
\hline$A L-P$ & $2.7 \sim 10.0 \mathrm{K.K}$. & 9.5 & 9.0 & 12.1 & 11.3 & 11.6 & 10.0 & 8.6 & 8.7 & 11.6 & 11.0 & 11.6 \\
\hline$\gamma$-GTP & $0 \sim 40 \mathrm{MU} / \mathrm{MI}$ & 38 & 69 & 69 & 41 & 48 & 36 & 37 & 45 & 49 & 51 & 49 \\
\hline Cholinesterase & 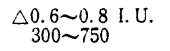 & 0.91 & 0.97 & 1.08 & 1.07 & 0.89 & 0.99 & 681 & 725 & 606 & 642 & 609 \\
\hline ZTT & $4 \sim 12 \mathrm{U}$ & 6.7 & 5.6 & 6.9 & 7.5 & 5.8 & 7.0 & 6.1 & 5.4 & 5.3 & 5.4 & 5.3 \\
\hline CCLF & $(-)$ & - & - & - & - & & & & & & & \\
\hline TTT & $0 \sim 5 \mathrm{U}$ & 2.8 & 11.9 & 6.5 & 5.5 & 3.8 & 2.7 & 3.3 & 2.4 & 3.3 & 3.0 & 3.3 \\
\hline Total Cholesterol & $130 \sim 250 \mathrm{mg} / \mathrm{dl}$ & 240 & 250 & 290 & 254 & 261 & 252 & 261 & 280 & 235 & 250 & 225 \\
\hline Au-antign-antibad & $-1-$ & $-1-$ & & & & & & & & & & \\
\hline$\gamma-\mathrm{gl}$ & $18.2 \sim 22 \%$ & 15.4 & 14.8 & 12.1 & 14.4 & 12.4 & 13.2 & 15.7 & 17.8 & & & 19.2 \\
\hline $\operatorname{Ig} G$ & $910 \sim 1550 \mathrm{mg} / \mathrm{dl}$ & & 870 & 1600 & 1350 & 1015 & & & & & & \\
\hline $\operatorname{Ig} \mathrm{A}$ & $167 \sim 409 \mathrm{mg} / \mathrm{dl}$ & & 145 & 268 & 190 & 184 & & & & & & \\
\hline $\operatorname{Ig} M$ & $40 \sim 250 \mathrm{mg} / \mathrm{dl}$ & & 120 & 176 & 120 & 104 & & & & & & \\
\hline I. C. G. & below ( $15^{\prime}$ value) & 9.8 & & & & & & & & & & \\
\hline
\end{tabular}




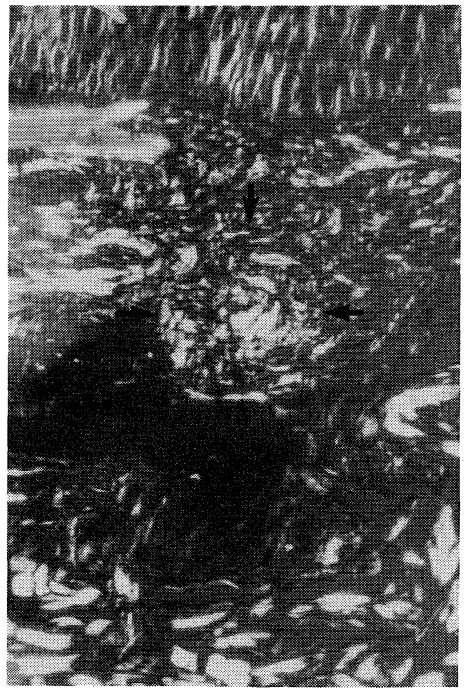

Case 2

Fig. 11. Amyloid deposits stained by Congred (skin). Birefringenc by polarization microscopy.

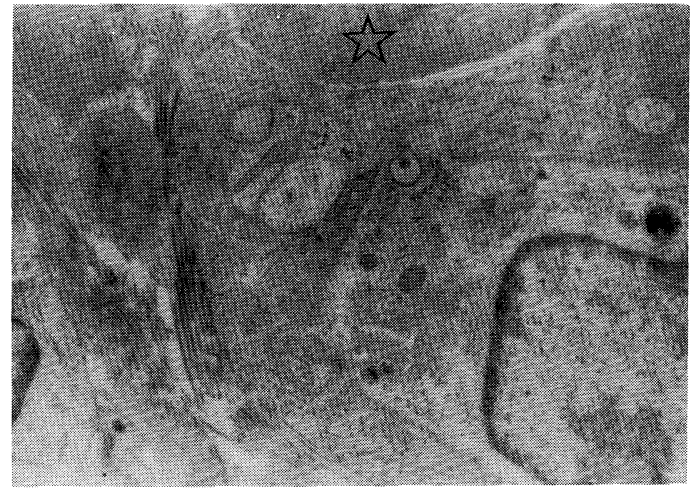

Case 2

Fig. 12. Electron microscopic findings near neuron. Notice amyloid fibrils form amyloid island.

and numbness over the flexior of the fingertips in August. Although she had not told any numbness for a certain period after that, she complained again of numbness on the lower extremities around Apr. 20, 1983. She also had acroparesthesia which was gradually alleviated. She has not suffered from that trouble since Aug. 24, 1983 up to now. Completely normal results were recorded for liver function tests. The skin biopsy indicated the findings similar to those of brother T.K. (Figs. $11,12)$. The conduction rates of peripheral nerves measured in March this year are normal.

\section{DISCUSSION}

In 1939, Andrade $^{5)}$ first reported a case with familiar polyneuropathy. Following this report, they also studied autopsy cases and detected deposition of amyloid not only in the region of peripheral nerves, but also in the kidney, skin, heart and liver. It is interesting that in a case reported in 1941 the presence of jaundice was recorded for consecutive four days. In a female of the other cases studied by them, it is hold that she had no families exhibiting such symptoms and that there were no persons with such a disease living around her. According to Isobe et al., amyloid deposition observed in patients with FAP is of the mixed type. That is, the region where amyloid deposition is observed widely varies from the whole body to each local tissue or organ. It has been demonstrated the cases in Portugal, Kumamoto and Nagano Prefectures in Japan revealed amyloid deposition in the skin. Particularly, a large quantity of amyloid was reported for cases found in Portugal. Clinical pathological studies of FAP performed by Shozo Kito detected the most significan deposition of amyloid in the heart and the kidneys, then in the pancreas and slight deposition of amyloid in the liver. He stained specimens by congored from liver and observed amyloid deposition in connective tissues and around central venous wslls as well. In symposium of Japanese Society of Internal Medicine in 1982, renal insufficiency and liver cirrhosis were listed as a part of the basic diseases for secondary amyloidosis. Araki first reported the occurrence of familiar polyneuropathy in Japan among two families consisting of 25 persons and living in Arao City, Kumamoto in 1970 and Kito reported this disease among 22 families consisting of 169 persons and living in Ogawa Village, Nagano in 1973. These researchers reported that familiar polyneuropathy found in these cases were of the Portuguese type. Investigation performed in 1979 proved 7 families with this disease in Kumamoto Prefecture, 35 families in Nagano Prefecture and one family in each of Shimane, Ishikawa, Kochi and Hyogo Prefectures. There are large focuses in Kumamoto and Nagano Prefectures while our cases are new type of FAP. The precursor protein for familiar amyloidosis is pre- 
albumin. In familiar amyloidosis of the Andrade type, amyloid deposition originates in peripheral blood vessels.

DMSO administration was attempted on patients with FAP living on Ogawa Village, Nagano and improvement of symptoms such as diarrhea, constipation and nausea was observed in 8 out of 18 cases and of sensory disorder in 9 out of 18 cases. Of the cases found in Ogawa Village, Mori ${ }^{7)}$ et al., Gifu University repoted two (without any finding suggesting systemic amyloidosis) in which amyloid deposition around sweat ducts and blood vessels was detected. These cases were resistant to potassium permanganate treatment. Araki ${ }^{8)}$ et al. measured the conduction rates of peripheral nerves and analyzed $\mathrm{N}$ waves in patients with FAP. They found that a patient with FAP after three years had a electrical response and the amplitude of $\mathrm{N}$ waves decreases from the early stage of the disease followed by proceeding the point at which the conduction rate begins to decrease. In the present case as well, notably decreased conduction rates were recorded for the lower extremities. By means of through DNA $^{9)}$ analysis, it wsa noticed that the type of this patient found was different from those in the patients living in the two large focuses consisting of Nagano and Kumamoto. A recent report on the production mechanism of amyloid states that prion is responsible for the deposition of amyloid in central nerves ${ }^{10}$. We also found viral particles in the liver of a female suffering from amyloidosis and incomplete neuropathy with chronic hepatitis which proved due to autoimmune mechanism. The work is still going on.

\section{REFERENCES}

1) Araki S, Mawatari S, Ohta M, et al: Polyneuroliticamyloidosis in Japanese family. Archives of Neurology 18: 1968 .

2) Kito S: A big focus at Ogawa Village in Nagano Prefecture of familiar amyloid polyneuropathy, Familiar polyneuropathy research group belonging Japanese Health and Welfare Ministry, 1973.

3) Ohhashi M, Morita S and Shigeno H: Cephalantin therapy for primary cutaneous amyloidosis. Amyloidotic Neuropathy Research Committee, Japan, 1980

4) Osserman EF, Isobe $\mathrm{T}$ and Farhangi M: Effect of DMSO in the treatment of Amyloidosis-Amyloidosis edited by Weaglelius $\mathrm{O}$, et al. Academic Press, 1976, p 553.

5) Andrade C: A peculiar form of peripheral neuropathy familiar atypical generalized amyloidosis with special involvement of the peripheral nerves. Brain 75: 408, 1952.

6) Isobe $T$, Ohhashi $M$ and Masuko K: The significance of urine examination for Bence-Jones protein in combination with EM study in skin amyloidosisamyloidosis EARS, 1981.

7) Mori S, Yanagihara M, Fukushima N, et al: Dermatological finding of skin in familiar amyloid polyneuropathy-Amyloid neuropathy research group in Health and Welfare Ministry, 1980.

8) Araki S, Tsuruta K, Kurihara T, et al: Nerve conduction and M-move studies-Research group of Health and Welfare Ministry, 1979.

9) Personal communication.

10) De Armond SJ, McKinley MP, Bany RA, et al: Identification of prion amyloid filaments in Scrapieinfected brain. Cell 41: 1, 221, 1985. 